de metade dos doentes, correspondem a múltiplos carcinomas basocelulares, quistos epidermoides, pitting palmo-plantar, calcificações intracranianas, anomalias das costelas e das vértebras e fácies característica (aumento do perímetro craniano, hipertelorismo e bossa frontal proeminente). A ocorrência de meduloblastoma, embora menos frequente, não é incomum. Descrição do caso clínico: Doente do género masculino, 9 anos de idade, com antecedentes de meduloblastoma e S. Gorlin confirmado geneticamente, recorreu ao Serviço de Urgência do Hospital de São João por tumefação intraoral. Objetivou-se: fácies compatível com S. Gorlin; dentição mista com alterações da forma (dentes conoides e microdentes); abaulamento vestibular no $1 .^{\circ}$ quadrante distal a 1.2; e abaulamento vestibular abrangendo todo o $5 .^{\circ}$ sextante. Ambas as tumefações exibiam consistência dura e não eram observáveis fístulas. A ortopantomografia revelou uma lesão radiotransparente multiloculada no $5 .^{\circ}$ sextante, condicionando desvio inferior de 4.3 incluso e levantava suspeita sobre a existência de lesões nos restantes sextantes. Por este motivo, foi realizada uma tomografia computorizada, que revelou a existência de 3 lesões líticas: na sínfise mentoniana $(29 \times 14 \mathrm{~mm})$; no $1 .^{\circ}$ quadrante (12x9mm) condicionando desvio anterior de 1.3 incluso; e outra em relação com 2.3-2.4. Procedeu-se a descompressão quística da lesão da sínfise mentoniana, dadas as suas dimensões e efetuou-se biópsia da parede quística, cuja análise anátomo-patológica foi compatível com queratoquisto odontogénico. Discussão e conclusões: O comportamento dos queratoquistos odontogénico na S. Gorlin é semelhante ao dos casos não sindrómicos, podendo cursar com intercorrências infeciosas e deformidade facial (grande potencial de crescimento). Deste modo, torna-se imperativa a excisão destes quistos. Dadas as dimensões da lesão mandibular, efetuou-se descompressão quística prévia, de modo a reduzir o risco de fratura inerente à excisão. A recorrência é muito comum, pelo que o seguimento a longo prazo é essencial.

http://doi.org/10.24873/j.rpemd.2019.12.493

\section{\#030 Enxerto de tecido conjuntivo subepitelial para o tratamento da recessão gengival}

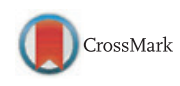

Olga Vascan*, Diana Breda, Melissa Marques, Maria Morais, Francisco Marques, José Pedro Figueiredo

Centro Hospitalar e Universitário de Coimbra, Centro Hospitalar e Universitário de Coimbra. Faculdade de Medicina da Universidade de Coimbra

Introdução: A recessão gengival pode ser definida como a localização apical da margem gengival em direção à junção muco-gengival, ocasionando exposição da superfície radicular. Múltiplas ou isoladas, as recessões gengivais têm diversos fatores desencadeantes, como inflamação, escovagem traumática, mal-posicionamento dentário e fatores iatrogénicos; sendo necessária a sua resolução antes do tratamento. A terapêutica é influenciada pelas quantidade de gengiva queratinizada, espessura gengival, lesões cervicais, altura/largura das papilas. O tratamento mais indicado é a cirurgia de enxerto gengival de epitélio (enxerto gengival livre) e o enxerto de tecido conjuntivo subepitelial. Relatamos um caso clínico de uma cirurgia de enxerto de tecido conjuntivo subepitelial pela técnica de tunelização. Descrição do caso clínico: do Homem, 48 anos, referenciado por sensibilidade dentária no dente 31 e comprometimento estético relacionado com recessão gengival com $5 \mathrm{~mm}$. No status radiográfico não se verificou perda óssea interproximal. Esta recessão gengival corresponde ao RT1- (Caton, 2018) ou classe II de Miller. Neste caso, optou-se por cirurgia de enxerto de tecido conjuntivo subepitelial pela técnica de tunelização. Realizada antissepsia muco-cutânea, procedeu-se à anestesia terminal infiltrativa e incisão intrassulcular no dente 31 sem envolvimento das papilas adjacentes. Após desbridamento radicular com curetas de Gracey, com o bisturi de tunelização preparou-se o túnel para o enxerto conjuntivo até aos dentes contíguos. Com o leito receptor preparado, foi obtido o enxerto de tecido conjuntivo subepitelial do palato pela técnica de envelope de Zucchelli. Com o enxerto posicionado, foram realizadas suturas com fio monofilamento (removidas ao $20 .^{\circ}$ dia do pós-operatório). Presentemente, o doente encontra-se no $2 .^{\circ}$ mês de seguimento, não apresentando qualquer recidiva. Discussão e conclusões: A selecção da técnica cirúrgica depende de cada caso. O objetivo do recobrimento radicular visa a obtenção de um bom resultado estético, prevenção de cárie radicular e eliminação de sensibilidade, possibilitando, assim, uma melhor higienização. No caso abordado, conseguiu-se um aumento de gengiva queratinizada com um bom recobrimento radicular, que conduziu a uma diminuição significativa da híper-sensibilidade dentinária e a uma melhoria significativa da estética.

http://doi.org/10.24873/j.rpemd.2019.12.494

\#031 Quando um abcesso odontogénico se revela um linfoma: relato de caso clínico

Cristina Moreira, Isabel Magalhães, Carina Ramos, Teresa Corrales*, Sónia Viegas

Centro Hospitalar de Vila Nova de Gaia/Espinho, Centro Hospitalar Universitário de São João

Introdução: Os linfomas constituem uma patologia maligna heterogénea, caraterizada pela proliferação de células linfóides ou seus precursores. Representam 2,2\% de todas as neoplasias malignas da cabeça e pescoço, sendo apenas ultrapassados pelo carcinoma epidermóide. O seu diagnóstico é desafiante por poderem mimetizar diversas patologias, como abcesso odontogénico, doença periodontal, osteomielite ou mesmo outras neoplasias. Descrição de caso clínico: Género feminino, 87 anos, antecedentes de hipertensão arterial, hipotiroidismo e fibrilhação auricular. Recorreu ao Serviço de Urgência por tumefação submandibular direita dolorosa, com 2 meses de evolução e agravamento nas últimas 3 semanas, após extração dentária no $4 .^{\circ}$ quadrante. Havia cumprido antibioterapia (Amoxicilina Ácido Clavulânico seguida de Clindamicina) sem melhoria. Realizou TC maxilofacial revelando eventual processo inflamatório, pelo que foi internada para antibioterapia endovenosa. Ao 4 . $^{\circ}$ dia, por manutenção do quadro, foi pedida observação por Estomatologia: tumefação submandibular direita, dura, sem sinais inflamatórios ou flutuação; intraoralmente sem drenagens ou abaulamentos. Após 
discussão com Radiologia, pedida TC com contraste, que não conseguiu excluir neoplasia maligna. Realizada biópsia aspirativa, cuja citologia e imunohistoquímica apontaram para processo linfoproliferativo. De seguida, uma biópsia ganglionar cervical confirmou o diagnóstico de Linfoma Difuso de Grandes Células B. A doente foi orientada para Consulta de Hemato-Oncologia e iniciou quimioterapia. Discussão e conclusões: Os linfomas não apresentam predileção de género e manifestam-se geralmente após a $7 .^{\text {a }}$ década de vida. Pela sua raridade, todos os relatos de caso são importantes para cimentar o conhecimento existente. Os achados intraorais mais frequentes incluem ulcerações, dor, edema e mobilidade dentária, enquanto extraoralmente se pode objetivar assimetria facial e linfadenopatias cervico-faciais, mimetizando outras patologias e levando muitas vezes a longos e ineficazes cursos de antibióticos, como neste caso. O atraso no diagnóstico e o tratamento incorreto conduzem, inevitavelmente, ao agravamento do prognóstico. É necessária elevada suspeição clínica, sendo a imagiologia uma ajuda na orientação diagnóstica. Contudo, a confirmação requer exame anatomopatológico. O Linfoma Difuso de Grandes Células B é agressivo e de curso clínico variável, embora remissões iniciais de 60-80\% sejam relatadas com quimioterapia.

http://doi.org/10.24873/j.rpemd.2019.12.495

\section{\#032 Hiperplasia Gengival: Excisão Cirúrgica} vs Laser CO2 - a propósito de um caso

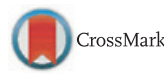

Daniela Rôlo*, Manuel Guedes, Fernando Milheiro, Ana Teresa Carapenha, Francisca Castro Lopes, Rui Moreira

Centro Hospitalar Universitário do Porto

Introdução: A hiperplasia gengival, de etiologia multifactorial, consiste num crescimento anormal dos tecidos gengivais. O seu tratamento, variável consoante a causa, deve incluir medidas profiláticas locais para minimizar os efeitos inflamatórios e/ou sistémicos mas também alguns procedimentos cirúrgicos como excisão cirúrgica convencional e laserterapia. Este trabalho pretende apresentar um caso de hiperplasia gengival num contexto de Neurofibromatose tipo 1 (NF1) com compromisso estético, em que se realizou a excisão de lesões através de dois diferentes métodos: excisão cirúrgica a frio e através de laser de CO2. Descrição do caso clínico: Doente de 17 anos, do género feminino, com antecedentes de NF1, referenciada à consulta de Estomatologia por apresentar hiperplasia gengival nodular generalizada, de consistência fibrosa, indolor e aumento das papilas fungiformes da língua, com vários anos de evolução. De forma a promover a componente estética e a melhoria no controle da saúde periodontal, realizou-se gengivectomia com bisturi, ao nível dos molares superiores do $2 .^{\circ}$ quadrante. Pela dificuldade sentida na hemostase durante o procedimento, realizou-se posteriormente, vaporização com laser pulsado de CO2 no lado contralateral. Recentemente, foi proposta para laserterapia sob anestesia geral para gengivectomia dos quatro quadrantes tendo, entretanto, recusado o procedimento por se encontrar satisfeita com os resultados obtidos. Discussão e conclusões: Apesar de infrequente, o envolvimento gengival na NF1 não pode ser desvalorizado, apresentando, para além de um desconforto local e estético, um potencial para complicações neurológicas e transformação maligna (5\%). Os neurofibromas podem ser removidos por remoção cirúrgica simples e laser de CO2. Neste caso, a utilização do laser de CO2 mostrou-se mais simples, rápida e com maior conforto para a doente, principalmente pelo controlo hemorrágico durante o procedimento. A cicatrização dos tecidos também se demonstrou de melhor qualidade, contudo, mais morosa e associada a maior sensação dolorosa, contrariando os resultados descritos em alguns estudos. É igualmente importante referir que o volume de tecido excisado na região submetida ao laser foi menor, podendo limitar a escolha deste procedimento. Podemos, assim, concluir que, pelo nível de conforto do operador e do doente, o laser de CO2 pode ser recomendado na cirurgia oral para a excisão de lesões de tecidos moles em doentes selecionados.

http://doi.org/10.24873/j.rpemd.2019.12.496

\section{\#033 Adenoma pleomórfico do palato - a propósito de um caso clínico}

José Ricardo Ferreira, Ana Teresa Coelho*, Cecília Franco Caldas, Miguel Amaral Nunes, Dolores López-Presa, Francisco Salvado

Centro Hospitalar Universitário Lisboa Norte, Serviço de Anatomia Patológica, Universidade de Lisboa, Faculdade de Medicina, Clínica Universitária de Estomatologia

Introdução: O adenoma pleomórfico é o mais frequente dos tumores de glândulas salivares. Em média, ocorre aos 45 anos e é mais frequente em homens. Afeta principalmente a glândula parótida, mas pode também atingir as glândulas salivares minor, mais frequentemente no palato. Apresenta-se como uma massa de crescimento lento e indolor, de superfície lisa e em forma de cúpula, aderente aos planos adjacentes. Histologicamente, é constituído por células ductais epiteliais e mioepiteliais, revestindo-se de uma cápsula de tecido conjuntivo, frequentemente incompleta ou infiltrada por células tumorais. O seu tratamento envolve a excisão do tumor com margens negativas. A recorrência é rara e o risco transformação maligna é de $5 \%$, mais frequente em casos avançados. Descrição do caso clínico: Homem de 45 anos, evacuado de São Tomé e Príncipe por lesão expansiva no palato com 3 anos de evolução, sem dor ou outros sintomas. Observava-se massa volumosa na vertente direita do palato duro, ultrapassando a linha média, de consistência fibroelástica, limites aparentemente bem definidos e fixa face aos planos adjacentes. A palpação cervical foi inocente. Colocou-se a hipótese diagnóstica de tumor de glândulas salivares minor do palato e solicitou-se ortopantomografia (OPG) e tomografia computorizada (TC) maxilofacial. Sob anestesia local, fez-se biópsia da lesão com bisturi circular, que revelou adenoma pleomórfico. A OPG não revelou lesões ósseas e a TC mostrou lesão de contornos arredondados, com $4 \mathrm{~cm}$ de maior diâmetro, centrada na metade posterior do palato à direita, elevando o pavimento e remodelando as paredes ósseas das fossas nasais e seio maxilar direito. Realizou-se res- 